\title{
Loss of Activin Receptor Type 2 Protein Expression in Microsatellite Unstable Colon Cancers
}

\author{
BARBARA JUNG, $*$ RYAN T. DOCTOLERO, ${ }^{\ddagger}$ AKIHIRO TAJIMA, ${ }^{*}{ }^{\ddagger}$ ALEXIE K. NGUYEN,* \\ TEMITOPE KEKU,§ ROBERT S. SANDLER,§ and JOHN M. CARETHERS*,ף,\|,ף \\ *Department of Medicine and "Rebecca and John Moores Comprehensive Cancer Center, University of California, San Diego, California; IVA \\ San Diego Healthcare System, San Diego, California; †Veterans Medical Research Foundation, San Diego, California; and \$Department of \\ Medicine, University of North Carolina, Chapel Hill, North Carolina
}

Background \& Aims: Colorectal tumors manifesting high-frequency microsatellite instability (MSI-H) develop genetically as a consequence of mutations in genes harboring repetitive DNA sequences. The activin type 2 receptor (ACVR2), possessing 2 polyadenine coding sequences, was identified as a mutational target, but it is not clear if expression is abrogated. Here, we analyzed MSI-H colorectal cancers for ACVR2 mutation and expression to assess if biallelic inactivation occurs. Methods: All $54 \mathrm{MSI}-\mathrm{H}$ colon cancers and 20 random microsatellite stable (MSS) tumors from a populationbased cohort of 503 patients were analyzed for mutations in $2 A_{8}$ tracts (exon 3 and 10) of ACVR2 and the $A_{10}$ tract of transforming growth factor $\beta$ receptor 2 (TGFBR2). Additionally, we sequenced exon 10 of ACVR2 in select cancers. ACVR2 expression was determined by immunohistochemistry using an antibody targeting an epitope beyond the predicted truncated protein. Results: Forty-five of $54 \mathrm{MSI}-\mathrm{H}$ cancers (83\%) showed mutation $\left(A_{8}\right.$ to $\left.A_{7}\right)$ in the polyadenine tract of exon 10 compared with no MSS tumors. Of tumors with mutant ACVR2, $62 \%$ lacked protein expression but all MSS and MSI-H tumors with wild-type ACVR2 expressed protein. We found no evidence of loss of heterozygosity at the ACVR2 locus in MSS tumors. Comparatively, 69\% of MSI-H cancers had frameshift mutation in TGFBR2. Conclusions: ACVR2 mutations are highly frequent in MSI-H colon cancers and in most cases cause loss of ACVR2 expression, indicating biallelic inactivation of the gene. Loss of activin signaling through mutation of ACVR2, similar to observations with TGFBR2, may be important in the genesis of MSI-H colorectal cancer.

C olorectal cancer develops as a consequence of genomic instability. There are 2 known forms of genomic instability that drive colon carcinogenesis: chromosomal instability (causing an aneuploid tumor) and microsatellite instability (MSI) (diploid tumors with multiple mutations as a result of inactivation of DNA mismatch repair). Both forms may require alteration of the WNT-signaling pathway, considered the "gate- keeper" for initiation of neoplasia in the colon. However, after initiation, the 2 forms of genomic instability take divergent pathways. In chromosomal unstable cancers, activation of K-RAS and inactivation of TP53 occur; in microsatellite unstable cancers, a variety of genes with coding microsatellite repeat sequences, including TGFBR2, BAX, bMSH3, bMSH6, and more recently $A C V R 2$, are targeted for frameshift mutation (reviewed by Carethers and Boland ${ }^{1}$ ).

$A C V R 2$ encodes a transmembrane receptor with serine threonine kinase activity. The protein transduces the signal when activin, a ligand from the transforming growth factor $\beta$ superfamily, binds to the extracellular domain of ACVR2. ${ }^{2}$ Once bound by activin, ACVR2 phosphorylates ACVR $1,{ }^{3}$ which causes a cascade of signaling events via phosphorylation of Smad2 and Smad3 in the cytoplasm. Subsequently, a heterocomplex forms with Smad4 and translocates into the nucleus to regulate gene transcription. ${ }^{4}$

The signaling cascade initiated by activin causes cellular differentiation and growth suppression. For instance, activin induces growth inhibition in T47D human breast cancer cells ${ }^{5}$ as well as in LNCaP prostate cancer cells ${ }^{6}$ and increases cell adhesion proteins in chicken limb buds. ${ }^{7}$ Downstream effectors of activin include the proto-oncogene $c-m y c^{6}$ and the p38 mitogenactivated protein kinase. ${ }^{5}$ Defective activin signaling also drives carcinogenesis. Mutant ACVR2 abolishes activinmediated erythroid differentiation. ${ }^{8}$ Additionally, blocking activin signaling in breast cancer cells abrogates activin-mediated growth arrest. ${ }^{5}$

A potential role for activin signaling in the colon recently came to light through a genome-wide search

Abbreviations used in this paper: MSI, microsatellite instability; MSI-H, high-frequency microsatellite instability; MSS, microsatellite stability.

(C) 2004 by the American Gastroenterological Association 0016-5085/04/\$30.00 doi:10.1053/j.gastro.2004.01.008 
("instabilotyping"). 9 ACVR2, which is expressed in the normal colon, ${ }^{10}$ was found mutated in $58 \%$ of 46 colorectal cancer cell lines with high-frequency microsatellite instability (MSI-H). ${ }^{9}$ A second study showed that $92 \%$ of 17 colorectal cancer cell lines and 7 xenografts from colon cancer lines with MSI-H had ACVR2 mutations. ${ }^{11}$ $A C V R 2$ mutations were primarily a frameshift in the $\mathrm{A}_{8}$ tract within exon 10. Another coding $A_{8}$ tract located in exon 3 was only affected in 2 of the cell lines. In that report, most cell lines had biallelic inactivation of the receptor based on allelic separation by cloning, but this has not been examined at the protein level.

Here, we analyzed prospectively collected primary colon cancer specimens obtained from a population-based study assessing MSI status for mutations in ACVR2. In particular, we performed immunohistochemistry to examine protein expression of ACVR2 using a specific antibody targeted to an epitope of the protein that is distal to the predicted truncation after frameshift mutation in ACVR2. We found that ACVR2 is not expressed in most MSI-H colon cancers with ACVR2 mutation.

\section{Materials and Methods}

\section{Patient Samples}

Colon tumor specimens were prospectively collected under Institutional Review Board approval as part of the North Carolina Colorectal Cancer Study, a population-based, case-control study comprising 503 patients. ${ }^{12}$ All tumor specimens were formalin fixed and paraffin embedded and then sliced into $5-\mu \mathrm{m}$ sections. A reference $\mathrm{H} \& \mathrm{E}$ stain was performed on one cut, and normal and tumor tissue were determined and marked for microdissection.

\section{Tissue Microdissection and DNA Extraction}

Enriched tumor tissue (minimally $75 \%$ tumor cells) and surrounding nontumor tissue were microdissected using a sterile scalpel blade. The microdissected tissue was then precipitated twice in $150 \mu \mathrm{L}$ xylene and $350 \mu \mathrm{L} 100 \% \mathrm{EtOH}$ followed by lyophilization. DNA was further purified with GeneReleaser (BioVentures, Murfeesboro, TN) and proteinase $\mathrm{K}$ digestion for 5 hours at $55^{\circ} \mathrm{C}$. The proteinase $\mathrm{K}$ was destroyed by heating the samples to $95^{\circ} \mathrm{C}$ for 15 minutes, and the samples were immediately iced for future analysis.

\section{Determination of MSI Status}

MSI status was determined in all 503 cancers from the North Carolina Colon Cancer Study using 5 MSI markers recommended by a National Cancer Institute panel. ${ }^{13,14} \mathrm{Am}$ plification and polymerase chain reaction analysis were performed as previously described. ${ }^{15}$ All MSI-H and randomly selected microsatellite stable (MSS) tumors from the North Carolina Colon Cancer Study cohort were examined in this study. MSI-H tumors were defined as having $\geq 2$ of 5 markers with novel alleles compared with matched nontumor DNA whereas MSS tumors had 0 of 5 markers with novel alleles.

\section{Amplification of the Polyadenine Tract in Exons 3 and 10 of ACVR2}

Specific primers were designed to amplify the polyadenine tracts in exon 3 and exon 10 of ACVR2 (exon 3: forward, 5'-TCTGCTTATTTATAGGACTGATTGTG-3'; reverse, 5'-CGCTGTGTGACTTCCATCTC-3'; exon 10: forward, 5'-GTTGCCATTTGAGGAGGAAA-3'; reverse, 5'CCTCTGAAAAGTGTTTTATTGGAA-3'). One primer from each set was radiolabeled with ${ }^{32} \mathrm{P}$, and DNA was amplified in a thermocycler (MJ Research, Waltham, MA) in a reaction containing $1 \mu \mathrm{mol} / \mathrm{L}$ of each primer, $1 \times$ reaction buffer, $100 \mathrm{ng}$ DNA template, $200 \mu \mathrm{mol} / \mathrm{L}$ deoxynucleotides, $1.5 \mu \mathrm{mol} / \mathrm{L}$ magnesium chloride, and $2.5 \mathrm{U}$ Taq polymerase. Polymerase chain reaction was performed over 29 cycles of $94^{\circ} \mathrm{C}, 54^{\circ} \mathrm{C}$, and $72^{\circ} \mathrm{C}$ of 1 minute each, preceded by a 3-minute denaturing step at $94^{\circ} \mathrm{C}$ and followed by a 10 minute extension step at $72^{\circ} \mathrm{C}$. After polymerase chain reaction, the product bands were analyzed on a $6 \%$ polyacrylamide gel and viewed with a phosphorimager (Molecular Dynamics, Sunnyvale, CA) for band shifts comparing the tumor DNA with the paired normal DNA.

\section{DNA Sequencing}

Tumor DNA samples were amplified with specific primers surrounding exon 10 of ACVR2. The correct product size was verified on a $2 \%$ agarose gel. The polymerase chain reaction product was purified using Microcon columns (Millipore Corp., Bedford, MA) and used in the presequencing reaction according to the manufacturer's protocol (Applied Biosystems, Foster City, CA) with either the specific forward or backward primer. Before sequencing, another purification step using Centri SEP columns (Princeton Separations, Adelphia, NJ) was performed and the product sequenced in an automated ABI 310 Genetic Analyzer (Applied Biosystems).

\section{Immunohistochemistry for ACVR2 Protein Expression}

Slides containing colon cancer tissue were deparaffinized in xylene and rehydrated in graded alcohols to water. The slides were immersed in sodium citrate buffer $(\mathrm{pH}$ 6.0) and heated in a microwave for 4 minutes for 4 times for antigen retrieval. Slides were then processed using a DAKO Signal Catalyzed Amplification System (DAKO Corp., Carpinteria, CA). Endogenous peroxidase activity was blocked by incubation with $\mathrm{H}_{2} \mathrm{O}_{2}$. Ten percent goat serum was added for 15 minutes to block nonspecific protein binding. Rabbit antiTyrGly mACVR2 (482-494) (a generous gift from W. Vale, Salk Institute) was incubated overnight and then rinsed with phosphate-buffered saline. Biotinylated anti-rabbit immunoglobulin $\mathrm{G}$ was added for 15 minutes, followed by incubation with peroxidase-labeled streptavidin for 15 minutes at room temperature. The sections were washed with phosphate-buff- 
ered saline, incubated with $3,3^{\prime}$-diaminobenzidine tetrahydrochloride and $\mathrm{H}_{2} \mathrm{O}_{2}$ for 1 minute, lightly counterstained with hematoxylin, dehydrated in graded alcohols, cleared in xylene, and coverslipped. Two investigators read the slides blindly. A tumor was considered negative for ACVR2 staining if there was no staining and positive if there was staining in $>50 \%$ of cells. There were no examples of intermediate $(0-50 \%)$ staining.

\section{Loss of Heterozygosity Analysis}

Assessment of loss of heterozygosity at the ACVR2 locus in MSS tumors was performed by polymerase chain reaction using $2{ }^{32} \mathrm{P}$-labeled primers for 2 markers (D2S1353: forward, 5'-CCAGGGACATTGCTTAACAT-3'; reverse, 5'-GAGCAGGATTTGTAACCCTG-3'; D2S1399: forward, 5'-CATTGGTCCAGGTAAACTGC-3'; reverse, 5'-TTCACAAGGTTCCACAAGGT-3') flanking ACVR2. Bands from paired tumor and nontumor DNA were analyzed on a $6 \%$ polyacrylamide gel, and intensity was quantified using a phosphorimager (Molecular Dynamics).

\section{Statistical Analysis}

Statistical analysis was performed using the $\chi^{2}$ test, with $P \leq 0.05$ indicating statistical significance.

\section{Results}

\section{MSI-H Colon Cancers Frequently Harbor Mutations in the $A_{8}$ Tract of Exon 10 of ACVR2, But Not in the $A_{8}$ of Exon 3 , and Occur as Frequently as TGFBR2 Mutations}

From the North Carolina Colon Cancer Study cohort of 503 patients with colon cancer, 54 patients $(11 \%)$ had tumors that were MSI-H. In this study, we analyzed all 54 patients with MSI-H tumors and 20 randomly selected patients with MSS tumors. Of the 54 MSI-H colon carcinomas analyzed, $83 \%$ showed a frameshift mutation within exon 10 , indicative of a deletion of one adenine from the $A_{8}$ tract (Figure 1 and Table 1). In contrast, none of the 20 control MSS tumors showed this shift (Table 1). None of the MSI-H or MSS colon tumors showed frameshift mutations of the polyadenine tract of exon 3 of $A C V R 2$ (data not shown).

To verify the results observed on the polyacrylamide gels, we performed DNA sequencing to determine where in exon 10 the frameshift mutation occurred. Wild-type $A_{8}$ was detected in the MSS tumors (Figure 2A). The MSI-H tumors that showed frameshift mutations in exon 10 of ACVR2 displayed a 1-base pair contraction in the amplified alleles at the $A_{8}$ tract (Figure $2 B$ ). This type of mutation is predicted to cause a premature stop codon resulting in truncation at amino acid 422 of the mature protein due to the shift in the reading frame at transla-

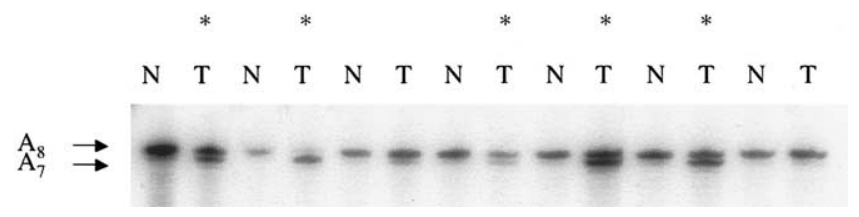

Figure 1. Frameshift mutation of the polyadenine $\left(A_{8}\right)$ tract in exon 10 of ACVR2 in MSI-H colon cancers. Seven representative MSI-H tumors are shown. Matching normal $(\mathrm{N})$ and tumor $(\mathrm{T})$ DNA was amplified using specific primers surrounding the $\mathrm{A}_{8}$ tract of exon 10 of ACVR2 and electrophoresed in adjacent lanes. A downward shift in band indicative of a deletion of one adenine in tumors is marked with asterisks. Tumors with both $A_{8}$ and $A_{7}$ alleles could be heterozygous for both wild-type and mutant alleles, or their DNA contains mixed tumor and nontumor cell populations.

tion and loss of wild-type ACVR2 protein expression with biallelic inactivation.

We also analyzed the same samples for frameshift mutations within the coding $\mathrm{A}_{10}$ tract of TGFBR2, previously reported to be the most commonly mutated gene in MSI-H colorectal cancers. ${ }^{16}$ The frequency of mutations in the polyadenine tract of TGFBR2 in our tumor samples was $69 \%$ (Table 1$)(P=0.07$ vs. $A C V R 2$ mutations). Of the 9 MSI-H tumors (17\%) without ACVR2 mutations, only $4(44 \%)$ had TGBR2 mutations.

\section{Loss of ACVR2 Protein Expression Occurs in MSI-H Colon Tumors With ACVR2 Mutations}

We performed immunohistochemistry on the MSI-H and MSS colon samples using an ACVR2 antibody whose epitope is beyond that of the predicted truncated protein. Sixty-two percent of MSI-H colon tumors with mutations in the $A_{8}$ tract of exon 10 lacked ACVR 2 protein expression (Figure $3 A$ and $B$ ). In some MSI-H tumors with mutated ACVR2, loss of expression was observed in subpopulations of the tumor only (Figure $3 C$ ). All MSS tumors expressed wild-type ACVR2 protein in both normal and cancer tissues. However, 2 MSS tumors (10\%) showed partial loss of ACVR2 expression within some areas of the tumors (data not shown). All 9 MSI-H tumors without mutation in ACVR2 expressed ACVR2 protein in both normal and tumor tissue (Figure 3D).

\section{MSS Colon Cancers Lack Loss of Heterozygosity at the ACVR2 Chromosome Locus}

We analyzed the $A C V R 2$ gene locus for loss of heterozygosity in the MSS tumors using 2 linked markers. None of the MSS tumors had loss of heterozygosity at the ACVR2 site, including the 2 MSS samples that 
Table 1. Summary of the Frequency of ACVR2 Mutations, ACVR2 Protein Expression, Frequency of TGFBR2 Mutations, and Combined ACVR2 and TGFBR2 Mutations in MSI-H and MSS Colon Cancer Specimens in This Study

\begin{tabular}{lcccc}
\hline & $\begin{array}{c}\text { ACVR2 } \\
\text { mutation (\%) }\end{array}$ & $\begin{array}{c}\text { Loss of ACVR2 protein } \\
\text { expression (\%) }\end{array}$ & $\begin{array}{c}\text { TGFBR2 } \\
\text { mutation (\%) }\end{array}$ & $\begin{array}{c}\text { TGFBR2 and ACVR2 } \\
\text { mutation (\%) }\end{array}$ \\
\hline MSI status & & & & \\
MSI-H & $45 / 54(83)$ & $28 / 45(62)$ & $37 / 54(69)$ & $28 / 54(52)$ \\
MSS & $0 / 20(0)$ & $0 / 20(0)$ & $0 / 20(0)$ & $0 / 20(0)$ \\
$P$ value & $<0.001$ & $<0.001$ & $<0.001$ & $<0.001$ \\
\hline
\end{tabular}

had partial loss of ACVR2 protein expression (data not shown).

\section{Discussion}

Genes with coding microsatellite tracts are targets for frameshift mutation in MSI-H colorectal cancers, and their inactivation is believed to play a role in the pathogenesis of these tumors. In particular, a key component of transforming growth factor $\beta$ signaling, TGFBR2, has been shown to be inactivated at both alleles in MSI-H colorectal cancers. ${ }^{17}$ Recently, ACVR2 was identified as a target for frameshift mutation in MSI-H colorectal cancers. ${ }^{9}$ In this study, we show that not only is frameshift

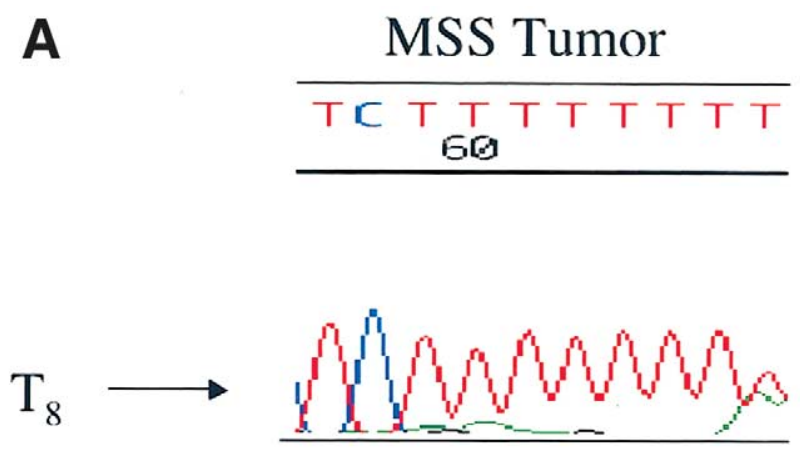

B
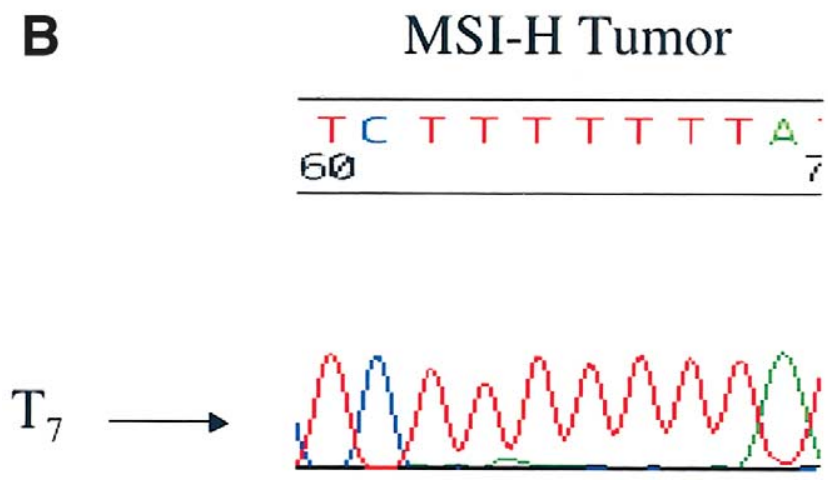

Figure 2. DNA sequences of the exon 10 polyadenine tract of ACVR2 in MSS and MSI-H tumors. (A) Representative MSS tumor showing only wild-type $\mathrm{T}_{8}$ in the reverse strand. (B) Representative MSI-H tumor that showed a frameshift on the polyacrylamide gel (Figure 1) has a 1-base pair contraction to $T_{7}$ in the reverse strand. mutation of $A C V R 2$ highly frequent in primary MSI-H colon cancers but also that there is complete loss of protein expression of this receptor, clearly indicating that both alleles that encode this tumor suppressor are inactivated.

We found that $A C V R 2$ frameshift mutations are as frequently detected in MSI-H tumors as frameshift mutations of TGFBR2. The consequence of this is not fully known. It is clear that both ACVR2 and TGFBR2 are involved in signaling pathways that suppress growth, control differentiation, and may induce cell death. ${ }^{1,5,18}$ Thus, mutation of either or both ACVR2 and TGFBR2 should abate growth suppression and contribute to progression of colorectal cancer. Indeed, in our study, both receptors were mutated in $52 \%$ of MSI-H tumors and TGFBR2 mutations were less common (44\%) if ACVR2 was not mutated. We speculate that both gene mutations are contributing to the pathogenesis of MSI-H colorectal cancers, may have some overlapping features on growth characteristics, and are acquired in a stepwise fashion. In particular, mutation of TGFBR2 seems to occur at the adenoma-to-carcinoma interface, suggestive of a role in malignant transition in MSI-H tumors. ${ }^{19}$ This has not been studied with $A C V R 2$.

$A C V R 2$ has 2 coding polyadenine tracts: one in exon 3 and one in exon 10. Only the exon 10 tract is mutated in our primary colorectal cancer samples, which is consistent with 2 previous reports.9,11 The predilection for exon 10 as the main site for mutation is intriguing because mutation in either adenine tract would be predicted to truncate the protein and inactivate its signaling function. We can only surmise that there is an affinity for the exon 10 tract to mutate in the absence of a functional DNA mismatch repair system.

The loss of expression of ACVR2 in our tumors can indicate problems at the level of DNA, transcription, or translation. In our MSI-H tumors, frameshift mutation of the exon 10 polyadenine tract $\left(A_{8}\right.$ to $\left.A_{7}\right)$ is the cause for loss of expression of ACVR2. We also found 2 MSS and 2 MSI-H tumors that had partial loss of ACVR2 expression within cell subpopulations of those tumors. In the MSI-H tumors, the area of ACVR2 protein loss represents clonal expansion of a subclone with biallelic 

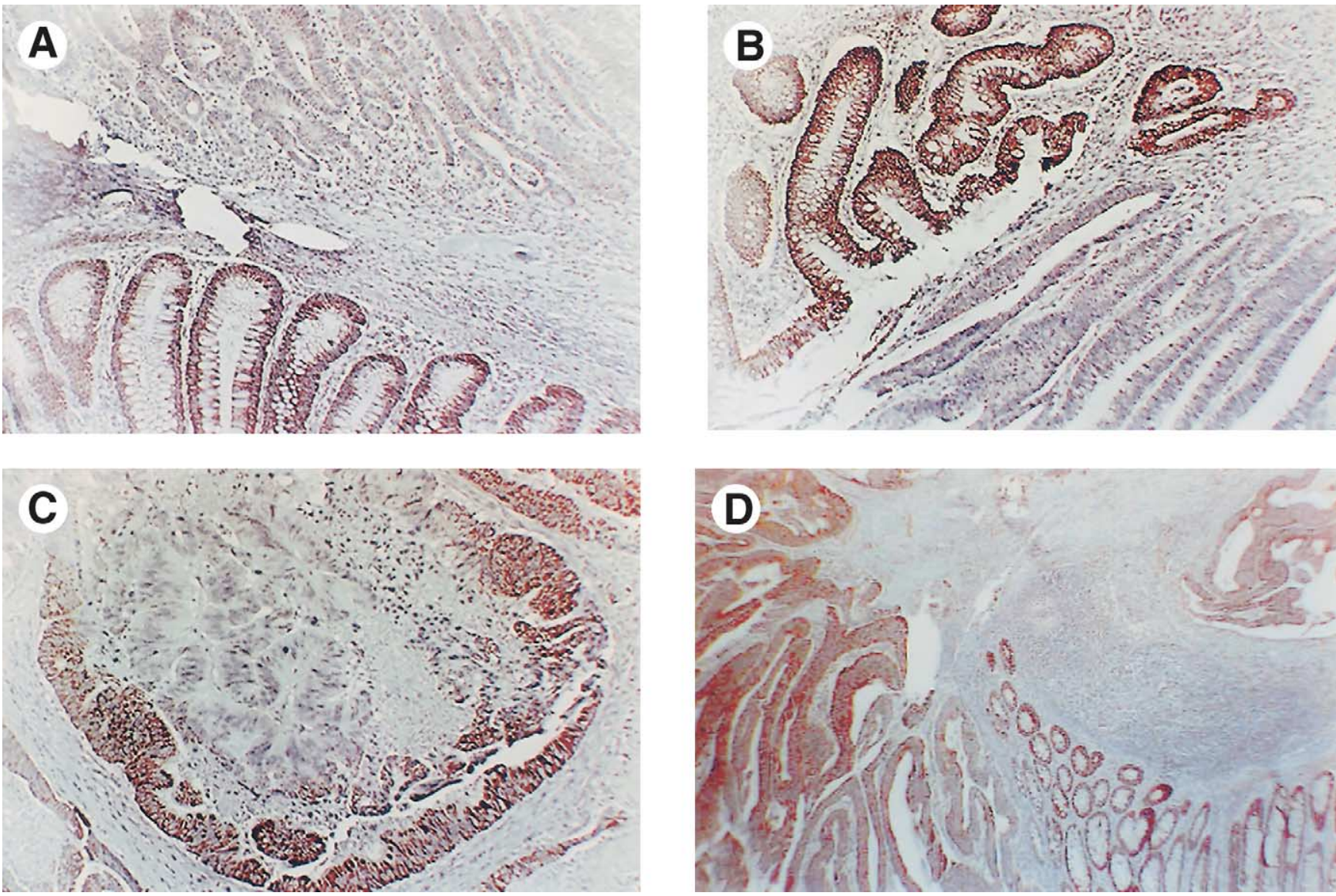

Figure 3. ACVR2 protein expression in MSI-H colon tumors. Tumors were incubated with an ACVR2 antibody that targeted near the carboxyl terminus of the receptor, beyond the predicted truncation from a frameshift mutation within exon 10 . $(A$ and $B)$ Examples of MSI-H tumors that showed ACVR2 frameshift mutation. Note the expression of ACVR2 protein in normal colonic epithelium and loss of expression in the adenocarcinoma. $(C)$ MSI-H tumor with mutated ACVR2 showing loss of protein expression within subpopulations of the tumor only. (D) MSI-H tumor with wild-type ACVR2 expressing ACVR2 protein in both normal and tumor tissue.

inactivation of ACVR2, whereas areas of expression may have heterozygous ACVR2 alleles leaving one wild-type allele competent to encode protein. However, loss of heterozygosity and DNA analysis of both exons 3 and 10 of ACVR2 from the MSS tumors did not yield a cause for partial loss of expression. We suggest that either epigenetic inactivation or mutation that does not involve the polyadenine tracts of $A C V R 2$ may be operative to cause loss of ACVR2 expression from a clonal population of cells within these MSS tumors.

Conversely, we identified 9 MSI-H tumors that fully express ACVR2 protein. This suggests that one or both alleles of ACVR2 are transcribed and translated appropriately. If activin signaling is a major target for inactivation, then it is possible that other components of activin signaling separate from ACVR2 mutation could be affected, although this is not known at this time. There are examples of other mechanisms to inactivate transforming growth factor $\beta$ signaling in MSI-H colorectal cancers aside from the dominantly observed mech- anism of TGFBR2 mutation, ${ }^{20}$ and we suspect that similar mechanisms might occur with activin signaling.

In summary, our data show that the polyadenine tract of exon 10 of ACVR2 is mutated in $83 \%$ of MSI-H colorectal cancers and is as frequently mutated as TGFBR2. The frameshift mutation of ACVR2 is associated with loss of ACVR2 protein in most MSI-H tumors, indicating biallelic inactivation. MSS tumors do not harbor this mutation and fully express ACVR2 protein, although we found 2 examples of partial loss of ACVR2 expression. These findings underscore the potential importance of loss of activin signaling in the pathogenesis of colorectal cancer. Further studies to decipher the function of activin signaling in colorectal cancer will likely yield important insight into colorectal tumorigenesis.

\section{References}

1. Carethers JM, Boland CR. Neoplasia of the gastrointestinal tract. In: Yamada T, Alperts DH, Kaplowitz N, Laine L, Owyang C, Powell 
DW, eds. Textbook of gastroenterology. 4th ed. Philadelphia: Lippincott-Raven, 2003:557-583.

2. Gray PC, Greenwald J, Blount AL, Kunitake KS, Donaldson CJ, Choe S, Vale W. Identification of a binding site on the type II activin receptor for activin and inhibin. J Biol Chem 2000;275: 3206-3212.

3. Carcamo J, Weis FM, Ventura F, Wieser R, Wrana JL, Attisano L, Massague J. Type I receptors specify growth-inhibitory and transcriptional responses to transforming growth factor beta and activin. Mol Cell Biol 1994;14:3810-3821.

4. Chen YG, Lui HM, Lin SL, Lee JM, Ying SY. Regulation of cell proliferation, apoptosis, and carcinogenesis by activin. Exp Biol Med (Maywood) 2002;227:75-87.

5. Cocolakis E, Lemay S, Ali S, Lebrun JJ. The p38 MAPK pathway is required for cell growth inhibition of human breast cancer cells in response to activin. J Biol Chem 2001;276:18430-18436.

6. Zhang Z, Zhao Y, Batres Y, Lin MF, Ying SY. Regulation of growth and prostatic marker expression by activin $A$ in an androgensensitive prostate cancer cell line LNCAP. Biochem Biophys Res Commun 1997;234:362-365.

7. Jiang TX, Yi JR, Ying SY, Chuong CM. Activin enhances chondrogenesis of limb bud cells: stimulation of precartilaginous mesenchymal condensations and expression of NCAM. Dev Biol 1993; 155:545-557.

8. Liu F, Shao LE, Yu J. Truncated activin type II receptor inhibits erythroid differentiation in K562 cells. J Cell Biochem 2000;78: 24-33.

9. Mori Y, Yin J, Rashid A, Leggett BA, Young J, Simms L, KuehI PM, Langenberg $P$, Meltzer SJ, Stine OC. Instabilotyping: comprehensive identification of frameshift mutations caused by coding region microsatellite instability. Cancer Res 2001;61:6046-6049.

10. Sonoyama K, Rutatip S, Kasai T. Gene expression of activin, activin receptors, and follistatin in intestinal epithelial cells. Am J Physiol 2000;278:G89-G97.

11. Hempen PM, Zhang L, Bansal RK, lacobuzio-Donahue CA, Murphy KM, Maitra A, Vogelstein B, Whitehead RH, Markowitz SD, Willson JK, Yeo CJ, Hruban RH, Kern SE. Evidence of selection for clones having genetic inactivation of the activin A type II receptor (ACVR2) gene in gastrointestinal cancers. Cancer Res 2003;63: 994-999.

12. Satia-Abouta J, Galanko JA, Martin CF, Potter JD, Ammerman A, Sandler RS. Associations of micronutrients with colon cancer risk in African Americans and whites: results from the North Carolina Colon Cancer Study. Cancer Epidemiol Biomarkers Prev 2003; 12:747-754.

13. Boland CR, Thibodeau SN, Hamilton SR, Sidransky D, Eshleman JR, Burt RW, Meltzer SJ, Rodriguez-Bigas MA, Fodde R, Ranzani GN, Srivastava S. A National Cancer Institute Workshop on Microsatellite Instability for cancer detection and familial predispo- sition: development of international criteria for the determination of microsatellite instability in colorectal cancer. Cancer Res 1998;58:5248-5257.

14. Carethers JM, Pham TT. Mutations of transforming growth factor beta 1 type II receptor, BAX, and insulin-like growth factor II receptor genes in microsatellite unstable cell lines. In Vivo 2000; 14:13-20.

15. Carethers JM, Hawn MT, Greenson JK, Hitchcock CL, Boland CR. Prognostic significance of allelic lost at chromosome 18q21 for stage II colorectal cancer. Gastroenterology 1998;114:11881195.

16. Parsons R, Myeroff LL, Liu B, Willson JK, Markowitz SD, Kinzler $\mathrm{KW}$, Vogelstein B. Microsatellite instability and mutations of the transforming growth factor beta type II receptor gene in colorectal cancer. Cancer Res 1995;55:5548-5550.

17. Markowitz S, Wang J, Myeroff L, Parsons R, Sun L, Lutterbaugh J, Fan RS, Zborowska E, Kinzler KW, Vogelstein B, et al. Inactivation of the type II TGF-beta receptor in colon cancer cells with microsatellite instability. Science 1995;268:1336-1338.

18. Valderrama-Carvajal H, Cocolakis E, Lacerte A, Lee EH, Krystal G, Ali S, Lebrun JJ. Activin/TGF-beta induce apoptosis through Smad-dependent expression of the lipid phosphatase SHIP. Nat Cell Biol 2002;4:963-969.

19. Grady WM, Rajput A, Myeroff L, Liu DF, Kwon K, Willis J, Markowitz $\mathrm{S}$. Mutation of the type II transforming growth factor-beta receptor is coincident with the transformation of human colon adenomas to malignant carcinomas. Cancer Res 1998;58: 3101-3104.

20. Grady WM, Myeroff LL, Swinler SE, Rajput A, Thiagalingam S, Lutterbaugh JD, Neumann A, Brattain MG, Chang J, Kim SJ, Kinzler KW, Vogelstein B, Willson JK, Markowitz S. Mutational inactivation of transforming growth factor beta receptor type II in microsatellite stable colon cancers. Cancer Res 1999;59:320_ 324.

Received September 10, 2003. Accepted December 29, 2003

Address requests for reprints to: John M. Carethers, M.D., GI Section (111D), VA San Diego Healthcare System, 3350 La Jolla Village Drive, San Diego, California 92161. e-mail: jcarethers@ucsd.edu; fax: (858) 552-4327.

Supported by a grant from the National Institute of Diabetes and Digestive and Kidney Diseases (T32-DK07202) and a Foundation for Digestive Diseases and Nutrition Fellow to Faculty Transition Award (to B.J.), a grant from the National Cancer Institute (R01-CA90231) (to J.M.C.), and a VA Merit Award (to J.M.C.).

The authors thank Katsumi Miyai, M.D., Ph.D., for expert assistance with interpretation of the tissue slides as well as Wylie Vale, Ph.D., for providing the ACVR2 antibody. 